\title{
Recent development in binderless fiber-board fabrication from agricultural residues: a review
}

\begin{abstract}
The manufacturing of fiberboard from wood fiber with the help of adhesive is highly developed and widely commercialized technique. However, with an increasing concern over health issues and biomass conservation, the fiberboards from agriculture residues with or without using adhesives are under intensive investigation. In last three decades, several researches have been done various methods and technique dealing the development of binderless fiber boards such as wet process and dry process. This review article also covered pretreatments of fiber which helps to find out optimum criteria for fabrication of fibreboards. Fibre sizes in fibreboard were studied and found that the dimensions of fibres effect the physical, mechanical and thermal properties. The pressing time and temperature influence the internal bonding of binderless fibreboards. The mechanical and thermal properties of binderless fibresboard were discussed on various pressing time and temperature and compared with different type fibreboards. Effect of hygrothermal properties on the physical, mechanical and thermal behavior of binderless were also discussed. This review summarized various aspects of self-bonding mechanism in binderless fibresboard with a focus on agriculture residues based raw materials. Various aspects of binderless fiberboard manufacturing such as raw material suitability, effects of pretreatments and manufacturing process on physical, mechanical and thermal properties are discussed. The chemical changes in fiber during pretreatments and hot pressing is also discussed in detail. These binderless fiberboard showed the suitability in use for indoor applications due to its non-toxic characteristics.
\end{abstract}

Keyword: Agriculture waste; Binderless fiberboard; Pretreatments; Pressing temperature; Mechanical properties and physical properties 